Comparison of the Effectiveness of Mindfulness-based Stress

\title{
Reduction Therapy and Emotion Regulation Training on the Distress Tolerance of Adolescent Girls with a Drug-Dependent Parent
}

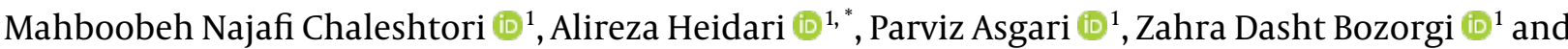 \\ Fariba Hafezi (iD ${ }^{1}$ \\ ${ }^{1}$ Department of Psychology, Ahvaz Branch, Islamic Azad University, Ahvaz, Iran \\ "Corresponding author: Department of Psychology, Ahvaz Branch, Islamic Azad University, Ahvaz, Iran. Email: heidaria945@gmail.com
}

Received 2021 October 31; Revised 2021 December 12; Accepted 2021 December 18.

\begin{abstract}
Background: The undesirable conditions resulting from addiction can be mitigated with timely diagnosis and effective interventions. Distress tolerance can be promoted in adolescents with a drug-dependent parent.

Objectives: The present study aimed to investigate the effectiveness of mindfulness-based stress reduction (MBSR) therapy and emotion regulation training (ERT) on the distress tolerance of adolescent girls with a drug-dependent parent in Ahvaz, Iran.

Methods: This clinical trial was performed on the experimental and control groups as the pretest-posttest design with follow-up. The statistical population included all the adolescent girl students with a drug-dependent parent in Ahvaz. The sample consisted of 45 adolescents with a drug-dependent parent selected by cluster sampling. The participants were randomly divided into two experimental groups of MBSR (eight 60-min sessions) and ERT (eight 45-min sessions) and a control group ( $\mathrm{n}=15$ per group). All three groups were followed up after 45 days. The research instrument was the Distress Tolerance Scale(DTS), and data were analyzed using the analysis of covariance.

Results: MBSR and ERT enhanced distress tolerance in adolescent girls with a drug-dependent parent $(\mathrm{P}<0.001)$. The effects of the two interventions were not significantly different, and this result persisted in the follow-up stage.

Conclusions: MBSR and ERT increased distress tolerance in adolescent girls with a drug-dependent parent. Therefore, these two interventions can be administered to enhance the mental health of adolescents.
\end{abstract}

Keywords: Addiction, Adolescents, Anxiety, Emotion Regulation, Mindfulness, Stress

\section{Background}

Many countries are currently afflicted with substance abuse, which has short- and long-term direct and indirect impacts on the quality of life and mental well-being (1, $2)$. Addiction refers to a state in which people lose their willpower to control actions due to psychological reasons or the consumption of natural or synthetic chemicals. Although weak willpower is not a disease in itself, it is regarded due to its effects on the central nervous system (3). Addiction has wide-range severe consequences for families, economy, security, and the cultural growth of societies $(4,5)$.

As the pivotal social institution and the primary source of influence, family shapes the decision of people to undertake risky behaviors during childhood and adolescence (6). According to Whitten et al. (7), approximately 30 - 45\% of adolescents with a drug-using parent will have substance dependence in the future. Wen et al. (8) reported that narcotic use by family members could form other family members' narcotic use tendency as an observational model. It is known that adolescents with a drug-dependent parent have poor distress tolerance. Ellis et al. (9) defined distress tolerance as one's ability to experience and endure negative emotional states. As an individual difference variable, this construct refers to the capacity of an individual to experience and withstand emotional distress (10). In a misguided effort to cope with negative emotions, people with low distress tolerance suffer from behavioral dysregulation and try to alleviate their emotional pain through destructive behaviors, such as drug abuse (11).

Mitigating the signs and symptoms of addictive tendencies requires a long-term perspective and therapeutic measures to promote specific skills, including mindfulness, interpersonal efficacy, distress tolerance, and emotion regulation (12). A valuable technique for this pur- 
pose is mindfulness-based stress reduction (MBSR) therapy. Mindfulness is defined as the awareness of all the internal and external experiences at the moment focuses on three components, namely a non-judgmental view, elevated awareness, and concentration on the present moment. It helps people process their cognitive, physiological, and behavioral activities $(13,14)$. Several studies have reported the effectiveness of this therapy in alleviating psychological distress, promoting emotion regulation, improving parenting, as well as enhancing the selfefficacy and distress tolerance of the parents of children with physical and motor disabilities. Moreover, it may enhance distress tolerance and stress response, reduce posttraumatic stress disorder symptoms, and augment adolescents' distress tolerance, stress control, emotion regulation at school, mindfulness, and resilience (15-19).

Adolescents are deeply affected by emotions and emotion regulation (20). Emotion regulation treatment is an ongoing process involving response to the emotional setting. This therapy involves several cognitive processes or functional coping skills (e.g., behavioral inhibition and flexibility in attention) for a proper response to emotion and effective adaptation to the environment (21). Adolescents at the risk of narcotic use display various emotions in a social setting and fail to provide an influential delayed response to the environment. Therefore, successful emotion regulation depends on effective inhibition. According to the literature, this therapy could effectively mitigate addictive tendencies and raise distress tolerance among adolescents at the risk of narcotic use.

Furthermore, it promotes distress tolerance in children with attention-deficit/hyperactivity disorder and improves distress tolerance, as well as reducing depression and suicidal ideation in adolescents. Addiction has undesirable impacts on the distress tolerance of the family, especially that of adolescents in the critical milestone of identity formation $(22,23)$. The undesirable conditions resulting from addiction can be mitigated with timely diagnosis and effective interventions leading to promoted distress tolerance in adolescents with a drug-dependent parent.

\section{Objectives}

Accordingly, the present study aimed to investigate the MBSR and emotion regulation training (ERT) on distress tolerance of adolescents with a drug-dependent parent.

\section{Methods}

This clinical trial with a pretest-posttest design and a follow-up was performed on the statistical population of all adolescent girl students with a drug-dependent parent in Ahvaz, Iran, in the academic year of 2019 - 2020. Two out of the four districts of Ahvaz were randomly selected, and ten all-girls schools were randomly chosen out of the junior high schools in these districts. This study received the necessary approvals from the relevant organizations. Following the permission of school principals and the guidance of teachers and school counselors, students with a drug-dependent parent were identified, and their records were examined by teachers and counselors. The Distress Tolerance Scale (DTS) was administered to the participants. The inclusion criteria were scoring below the mean on the DTS, absence of severe physical and mental conditions, and written informed consent for participating in all the therapy sessions. The exclusion criteria entailed missing more than two sessions and moving to another school. The sample consisted of 45 adolescents with a drug-dependent parent selected by cluster sampling. The participants were randomly divided into three groups of MBSR, ERT, and control ( $n=15$ per group). In the present study, $G^{*}$ power software was used to calculate the sample size with a test power of 0.95 and $\alpha=0.05$. Training sessions were held following the health protocols of the COVID-19 pandemic.

\subsection{Research Instrument}

\subsubsection{Distress Tolerance Scale}

The 15-item Distress Tolerance Scale (DTS) is a selfreport measure of emotional distress tolerance developed by Simmons and Gaher in 2005. The items measure distress tolerance based on the ability of an individual to withstand emotional distress, mental appraisal of distress, absorption of negative emotions, and regulatory measures to relieve distress. The items are scored based on a fivepoint Likert scale from 1 to 5 , where higher scores indicate greater distress tolerance. Moghadam et al. (24) reported that a Cronbach's alpha of 0.83 for the inventory indicates the good reliability of the scale. In the present study, Cronbach's alpha was 0.86 for the scale.

\subsubsection{Intervention Program}

The first intervention program consisted of eight 60min sessions (once a week) of MBSR. The second intervention program was eight 45-min sessions (once a week) of ERT. Tables 1 and 2 present a summary of sessions. The control group did not receive any intervention. To adhere to ethical principles, we administered intensive interventions to the control group after the follow-up.

\subsection{Statistical Analysis}

Data were analyzed by the descriptive and inferential statistics, including mean, standard deviation (SD), and analysis of covariance (ANCOVA). 


\begin{tabular}{|c|c|}
\hline Session & Content \\
\hline 1 & $\begin{array}{l}\text { Pretest, establishing a therapeutic relationship, getting to know each other, explaining the rules, setting the objectives and expectations, explaining the } \\
\text { nature of addiction, discussing addiction and its impacts on the lives of participants, and briefly introducing mindfulness and awareness while performing } \\
\text { daily activities }\end{array}$ \\
\hline 2 & $\begin{array}{l}\text { The fundamental assumptions of mindfulness, theoretical underpinnings of meditation, advantages and positive effects of meditation exercises, breathing } \\
\text { awareness technique, sitting medication, and recording a pleasant event }\end{array}$ \\
\hline 3 & $\begin{array}{l}\text { Introducing thoughts, mindful dealing with automatic negative thoughts, acceptance without futile effort and resistance, non-judgmental observation of } \\
\text { thoughts, observing the thoughts (brainstorming), and recording an unpleasant event }\end{array}$ \\
\hline 4 & $\begin{array}{l}\text { Introducing emotions, the difference between emotions and feelings, clarifying different types of positive, negative, and neutral emotions and how to } \\
\text { identify them, mindful dealing with negative, unpleasant emotions, finding the physical representation of emotion through mindfulness, releasing the } \\
\text { emotion-induced physical tension, observing and identifying emotions, and exploring emotions in the body }\end{array}$ \\
\hline 5 & $\begin{array}{l}\text { Different types of stress, stress cycle in the body, undesirable effects of stress on addictive tendencies, re-activation of addiction after stressful events, } \\
\text { strategies for coping with stress, 3-min breathing space, awareness of physical sensations, mindfulness of ambient sounds, and STOP exercise for stress } \\
\text { management }\end{array}$ \\
\hline 6 & $\begin{array}{l}\text { Effects of mindful states on pain management and relief, the five-step mindfulness solution to pain, exploring and identifying unpleasant physical } \\
\text { sensations (e.g., pain), awareness and consciousness of these sensations, acceptance and coping with pain, and body scan }\end{array}$ \\
\hline 7 & $\begin{array}{l}\text { The role of mindfulness in daily interactions and interpersonal relationships, mindful states in interactions and behaviors, the role of mindful states in the } \\
\text { identification and management of unpleasant mental states, emotions, and physical sensations that disrupt interactions, mindfulness in daily interactions }\end{array}$ \\
\hline 8 & $\begin{array}{l}\text { Review, expanding mindful states in personal and interpersonal life, discussing the changes occurring in their lives in the past sessions, a summary of the } \\
\text { course, posttest }\end{array}$ \\
\hline \multicolumn{2}{|c|}{ Table 2. Content of ERT Sessions (26) } \\
\hline Session & Content \\
\hline 1 & Pretest, establishing of a therapeutic relationship, conceptualization, and the necessity of emotion regulation training \\
\hline 2 & $\begin{array}{l}\text { A brief review of the previous session, awareness of different types of positive emotions (e.g., happiness, interest, love), attention to positive emotions, the } \\
\text { necessity of using positive emotions with examples as imagination, homework (i.e., recording major positive emotions in the worksheet) }\end{array}$ \\
\hline 3 & $\begin{array}{l}\text { A brief review of the previous session, awareness of different types of negative emotions (e.g., distress tolerance, sadness, anger, hatred), attention to } \\
\text { negative emotions, the necessity of using negative emotions with examples as imagination, homework (i.e., recording major negative emotions in the } \\
\text { worksheet) }\end{array}$ \\
\hline 4 & $\begin{array}{l}\text { Reviewing the previous session, non-judgmental acceptance of the (low or high) rate of positive emotions, positive and negative outcomes of using these } \\
\text { emotions, homework (i.e., surveying parents and close friends about the intensity of positive emotions and recording the answers in the worksheet) }\end{array}$ \\
\hline 5 & $\begin{array}{l}\text { Reviewing the previous session, non-judgmental acceptance of the (low or high) rate of negative emotions, positive and negative outcomes of using these } \\
\text { emotions, homework (i.e., surveying parents and close friends about the intensity of negative emotions and recording the answers in the worksheet) }\end{array}$ \\
\hline 6 & $\begin{array}{l}\text { A review of the previous session, the re-appraisal and expression of positive emotions, the imagination of positive emotions (e.g., happiness, interest, love), } \\
\text { cognitive inhibition, and appropriate expression of these emotions }\end{array}$ \\
\hline 7 & $\begin{array}{l}\text { A review of the previous session, the re-appraisal and expression of negative emotions, the imagination of negative emotions (e.g., distress tolerance, } \\
\text { sadness, anger, hatred), cognitive inhibition, and appropriate expression of these emotions }\end{array}$ \\
\hline 8 & Summary of the course, posttest \\
\hline
\end{tabular}

\section{Results}

The mean \pm SD of the age of MBSR and ERT groups was $14.52 \pm 2.27$ and $15.74 \pm 2.08$ years, respectively. In addition, the mean \pm SD of the age of the control group was $15.11 \pm 1.73$ years. Table 3 presents the mean \pm SD of the distress tolerance in the experimental and control groups in the pretest, posttest, and follow-up stages.

First, the assumptions of the ANCOVA were checked. The non-significant result of Kolmogorov-Smirnov $\mathrm{Z}$ indicated the normal distribution of the distress tolerance data $(Z=1.25, P=0.388)$. Moreover, Levene's test confirmed the homogeneity of the variances of the experimental and control groups $(\mathrm{F}=1.95, \mathrm{P}=0.151)$. An analysis of variance was performed to examine the assumption of regression line slope homogeneity, which was confirmed by a nonsignificant interaction $(F=3.61, P=0.218)$. Therefore, the data could be analyzed using the ANCOVA.

The F-ratio of the univariate ANCOVA for the dependent variable showed that MBSR therapy, emotion regulation training, and control group were significantly different in distress tolerance (Table 4). Therefore, at least one of the interventions significantly affected the dependent variable.

The MBSR therapy and ERT promoted distress tolerance in the posttest and follow-up. The difference in the means of the two experimental groups was 0.33 , indicating that posttest and follow-up distress tolerance were not signifi- 


\begin{tabular}{|c|c|c|c|c|c|}
\hline Variable & Phases & MBSR & ERT & Control & $\mathbf{P}$ \\
\hline \multirow{3}{*}{ Distress tolerance } & Pretest & $30.55 \pm 5.36$ & $29.90 \pm 5.59$ & $29.70 \pm 5.42$ & 0.418 \\
\hline & Posttest & $48.35 \pm 11.57$ & $47.35 \pm 11.51$ & $31.25 \pm 9.16$ & 0.001 \\
\hline & Follow-up & $49.45 \pm 12.01$ & $51.40 \pm 3.64$ & $29.90 \pm 4.95$ & 0.001 \\
\hline
\end{tabular}

${ }^{\text {a }}$ Values are expressed as mean $\pm \mathrm{SD}$.

\begin{tabular}{|c|c|c|c|c|c|c|c|c|}
\hline Variable & Phases & SS & df & MS & $\mathbf{F}$ & $\mathbf{P}$ & $\eta^{2}$ & Power \\
\hline \multirow{2}{*}{$\begin{array}{l}\text { Distress } \\
\text { tolerance }\end{array}$} & Posttest & 3431.35 & 2 & 1715.67 & 19.83 & 0.001 & 0.41 & 1 \\
\hline & Follow-up & 5674.49 & 2 & 2837.24 & 46.21 & 0.001 & 0.62 & 1 \\
\hline
\end{tabular}

cantly different between these groups (Table 5).

\section{Discussion}

Both MBSR therapy and ERT significantly enhanced distress tolerance in adolescent girls with a drug-dependent parent, and this effect persisted in the follow-up stage. The two interventions were not significantly different in distress tolerance improvement in the posttest and follow-up steps. This finding is consistent with the research results of Carpenter et al. (17) and Campbell et al. (18).

Adolescents with a drug-dependent parent constantly experience flashbacks to their parents' primary and painful emotional states in the search for drugs, which reduces their distress tolerance. With mindfulness training, they are encouraged to observe and accept their emotional experiences without altering them. Dealing with negative emotions in this manner may reduce stress impulsivity. As a result, people are encouraged to regard their emotions as transient events that do not necessitate maladaptive behaviors and reactions. This generalized view of emotions prevents emotional reactions from being re-experienced.

When people practice mindfulness in their daily activities, they can recognize when they are in a normal state and can live in the present moment, which in turn stops the cycle of events leading to unpleasant emotions and anxiety. Mindfulness meditation helps people creatively respond to the present state and releases them from automatic reactions. Body scan exercises with direct bodily sensations enhancing one's sensitivity to receiving physical messages and, in this way, mitigating mental distress (19). Mindfulness increases the awareness of self and the situation to deal with and survive crises with meditation techniques, such as mindful breathing. In this way, people will tolerate their physical and emotional pain in the short- and longterm.

With mindfulness, people realize that events occur in the present, which helps them perceive events as less disconcerting. The MBSR therapy enhances the metaemotional construct of distress tolerance (17). People pay attention to, appraise, accept, and tolerate negative emotions when they cannot change the situation. Therefore, they can regulate emotions, especially the tendency to avoid or immediately undermine the experience, and do not suffer dysfunction.

Furthermore, ERT improved distress tolerance in adolescents with a drug-dependent parent. This finding is consistent with the results of Bardeen et al. (22) and Russell et al. (27). The pivotal role of emotion regulation in dealing with stressful events, adaptive performance, and psychological well-being has been documented. It has been shown that people can adjust how they express emotions, known as emotion regulation. Emotion regulation is a key to starting, appraising, and organizing adaptive behavior and preventing negative emotions and maladaptive behaviors performed consciously or unconsciously in response to environmental demands (22).

Failure to regulate emotions is called emotion dysregulation, defined as a maladaptation to respond to emotions. Various physiological symptoms and disorders, including pain, tobacco use, the diagnostic symptoms of emotion dysregulation, and internalizing disorders (e.g., depression, anxiety), can be attributed to emotion dysregulation (23). According to Gratz and Roemer (28), emotion dysregulation or distress intolerance involves the nonacceptance of emotional responses, difficulties in goaldirected behaviors, impulse control difficulties, the lack of emotional awareness and clarity, as well as limited access to emotion regulation strategies.

Non-acceptance of emotional responses is translated into a sense of shame, anger, embarrassment, and being upset about negative emotions. The cycle of emotional pain goes on in people with emotion dysregulation and prevents the acceptance of emotional responses unless they stop their negative thoughts and induce positive ones to reduce their emotional distress and guilt coming from 


\begin{tabular}{|c|c|c|c|c|c|}
\hline Variable & Phases & Groups & Mean Difference & SE & $\mathbf{P}$ \\
\hline \multirow{5}{*}{ Distress tolerance } & \multirow{3}{*}{ Posttest } & MBSR-Control & 16.22 & 2.95 & 0.001 \\
\hline & & ERT-Control & 15.89 & 2.89 & 0.001 \\
\hline & & MBSR-ERT & 0.33 & 2.94 & 0.868 \\
\hline & \multirow[t]{2}{*}{ Follow-up } & ERT-Control & 21.52 & 2.47 & 0.001 \\
\hline & & MBSR-ERT & 1.88 & 2.48 & 0.92 \\
\hline
\end{tabular}

negative emotions. In addition to rejecting the existence of negative emotions, these people feel embarrassed and distressed by the existence of such emotions. As they fail to accept themselves, they find it difficult to behave in a goaldirected manner and have little concentration on their tasks.

People with poor distress tolerance also have trouble with impulse control and make extensive efforts to control impulses. In other words, they cannot resist impulses or motives that are pleasurable but hazardous to themselves and others. These people cannot resist impulses or temptations for doing something harmful to them or others. Consequently, it appears that emotional awareness improved distress tolerance in adolescents.

The two interventions did not significantly differ in terms of distress tolerance improvement. Overall, through MBSR therapy and emotion regulation training, the adolescents found different solutions to their problems with the help of their therapist, and this collaboration elevated their emotion regulation. Distress tolerance is one's ability to resist and experience negative emotional states. Those with poor distress tolerance describe distress as an unbearable construct.

Brainstorming is a mindfulness technique for dealing with intense and problematic emotions and offers a haven during distress. This technique allows people with low distress tolerance to view their internal world and concentrate on and accept internal experiences. Moreover, they can learn to control their anger and relieve pain through mindful anger management or non-aggressive interaction. Mindfulness and ERT allow people to get in touch with their frightening experiences, and with these exercises, they no longer avoid awareness of their physical sensations and thoughts to escape their impact. When people are lost in the past or future events, they simply forget that they are at the present moment and are absorbed by thoughts of the past or future as if they no longer live in the present.

The research population was limited to girls, and this prevents gender comparison. The results should be generalized to other populations with caution. Furthermore, the long duration of intervention sessions for the statistical population of the study, self-report questionnaires, and the small sample size could be mentioned as the other limitations of the present investigation. This study did not deal with the effect of cultural factors on the research variables. Further research is suggested to control other effective variables and compare their findings with those of the present study.

\section{Acknowledgments}

This article was extracted from a part of the Ph.D. dissertation of the first author in the Department of Psychology, Ahvaz Branch, Islamic Azad University, Ahvaz, Iran. The researchers would like to thank all the individuals who participated in the study.

\section{Footnotes}

Authors' Contribution: Mahboobeh Najafi Chaleshtori and Alireza Heidari, conceptualization and design, acquisition of data, analysis and interpretation of data, and statistical analysis; Parviz Asgari and Zahra Dasht Bozorgi, administrative, technical, and material support, and study supervision; Alireza Heidari and Fariba Hafezi, critical revision of the manuscript for important intellectual content.
Clinical
Trial
Registration
Code:

IRCT20201007048963N1

Conflict of Interests: No conflict of interest to declare.

Ethical Approval: The study was approved by the Ethical Committee of the Ahvaz Branch of Islamic Azad University (code: IR.IAU.AHVAZ.REC.1399.024).

Funding/Support: This study did not receive any funding.

Informed Consent: Written informed consent was provided for participating in all the therapy sessions. 


\section{References}

1. Carpenter CS, McClellan CB, Rees DI. Economic conditions, illicit drug use, and substance use disorders in the United States. J Health Econ. 2017;52:63-73. doi:10.1016/j.jhealeco.2016.12.009. [PubMed: 28235697].

2. Komasi S, Saeidi M, Amiri MM, Nazeie N, Shams Alizadeh N, Soroush A. Triggers of Substance Abuse Slip and Relapse During Outpatient Treatment in Methadone/Buprenorphine Maintenance Therapy Clinics: A Predictive Model with Emphasis on Treatment-Related Factors. Jundishapur J Health Sci. 2017;9(3). e57688. doi: 10.5812/jjhs.57688.

3. Basterfield C, Hester R, Bowden SC. A meta-analysis of the relationship between abstinence and neuropsychological functioning in methamphetamine use disorder. Neuropsychology. 2019;33(5):739-53. doi: 10.1037/neu0000552. [PubMed: 31021107].

4. Kolodny A, Courtwright DT, Hwang CS, Kreiner P, Eadie JL, Clark TW, et al. The prescription opioid and heroin crisis: a public health approach to an epidemic of addiction. Annu Rev Public Health. 2015;36:559-74. doi: 10.1146/annurev-publhealth-031914-122957. [PubMed: 25581144].

5. Saeidi M, Amiri MM, Ahmadi M, Komasi S. The Relationship Between the Enneagram Personality Types and Health Responsibility in Patients with Substance Use Disorder; a Brief Report. Jundishapur J Health Sci. 2019;11(2). e90424. doi: 10.5812/jjhs.90424.

6. Bo A, Hai AH, Jaccard J. Parent-based interventions on adolescent alcohol use outcomes: A systematic review and meta-analysis. Drug Alcohol Depend. 2018;191:98-109. doi: 10.1016/j.drugalcdep.2018.05.031. [PubMed: 30096640].

7. Whitten T, Burton M, Tzoumakis S, Dean K. Parental Offending and Child Physical Health, Mental Health, and Drug Use Outcomes: A Systematic Literature Review. J Child Fam Stud. 2019;28(5):1155-68. doi: 10.1007/s10826-019-01388-7.

8. Wen H, Hockenberry JM, Druss BG. The Effect of Medical Marijuana Laws on Marijuana-Related Attitude and Perception Among US Adolescents and Young Adults. Prev Sci. 2019;20(2):215-23. doi: 10.1007/s11121-018-0903-8. [PubMed: 29767282].

9. Ellis AJ, Salgari G, Miklowitz D, Loo SK. Is distress tolerance an approach behavior? An examination of frontal alpha asymmetry and distress tolerance in adolescents. Psychiatry Res. 2018;267:210-4. doi: 10.1016/j.psychres.2018.05.083. [PubMed: 29933213].

10. Keough ME, Riccardi CJ, Timpano KR, Mitchell MA, Schmidt NB. Anxiety symptomatology: the association with distress tolerance and anxiety sensitivity. Behav Ther. 2010;41(4):567-74. doi: 10.1016/j.beth.2010.04.002. [PubMed: 21035619]. [PubMed Central: PMC4490862].

11. Kozak AT, Davis J, Brown R, Grabowski M. Are overeating and food addiction related to distress tolerance? An examination of residents with obesity from a U.S. metropolitan area. Obes Res Clin Pract. 2017;11(3):287-98. doi: 10.1016/j.orcp.2016.09.010. [PubMed: 27793573].

12. Cook NE, Gorraiz M. Dialectical behavior therapy for nonsuicidal self-injury and depression among adolescents: preliminary metaanalytic evidence. Child Adolesc Ment Health. 2016;21(2):81-9. doi: 10.1111/camh.12112. [PubMed: 32680373].

13. Anheyer D, Leach MJ, Klose P, Dobos G, Cramer H. Mindfulnessbased stress reduction for treating chronic headache: A systematic review and meta-analysis. Cephalalgia. 2019;39(4):544-55. doi: 10.1177/0333102418781795. [PubMed: 29863407].

14. Khazami M, Dasht Bozorgi Z. Effectiveness of the MindfulnessBased Cognitive Therapy on Depression, Stress, and Anxiety Among COVID-19 Patients. Jundishapur J Health Sci. 2021;13(3). e117000. doi: $10.5812 /$ jjhs.117000.
15. Kolahkaj B, Zargar F, Majdinasab N. The Effect of Mindfulness-Based Stress Reduction (MBSR) Therapy on Quality of Life in Women with Multiple Sclerosis, Ahvaz, Iran. J Caring Sci. 2019;8(4):213-7. doi: 10.15171/jcs.2019.030. [PubMed: 31915623]. [PubMed Central: PMC6942645]

16. Pascoe MC, Thompson DR, Ski CF. Yoga, mindfulness-based stress reduction and stress-related physiological measures A meta-analysis. Psychoneuroendocrinology. 2017;86:152-68. doi 10.1016/j.psyneuen.2017.08.008. [PubMed: 28963884].

17. Carpenter JK, Sanford J, Hofmann SG. The Effect of a Brief Mindfulness Training on Distress Tolerance and Stress Reactivity. Behav Ther. 2019;50(3):630-45. doi: 10.1016/j.beth.2018.10.003. [PubMed 31030879]. [PubMed Central: PMC6494113].

18. Campbell AJ, Lanthier RP, Weiss BA, Shaine MD. The Impact of a Schoolwide Mindfulness Program on Adolescent Well-Being, Stress, and Emotion Regulation: A Nonrandomized Controlled Study in a Naturalistic Setting. J Clin Child Adolesc Psychol. 2019;5(1):18-34. doi: 10.1080/23727810.2018.1556989.

19. Nila K, Holt DV, Ditzen B, Aguilar-Raab C. Mindfulness-based stress reduction (MBSR) enhances distress tolerance and resilience through changes in mindfulness. Ment Health Prev. 2016;4(1):36-41. doi: 10.1016/j.mhp.2016.01.001.

20. Boyle CC, Stanton AL, Ganz PA, Crespi CM, Bower JE. Improvements in emotion regulation following mindfulness meditation: Effects on depressive symptoms and perceived stress in younger breast cancer survivors. J Consult Clin Psychol. 2017;85(4):397-402. doi: 10.1037/ccp0000186. [PubMed: 28230391]. [PubMed Central: PMC5364040]

21. Bernstein EE, McNally RJ. Acute aerobic exercise helps overcome emotion regulation deficits. Cogn Emot. 2017;31(4):834-43. doi: 10.1080/02699931.2016.1168284. [PubMed: 27043051].

22. Bardeen JR, Tull MT, Dixon-Gordon KL, Stevens EN, Gratz KL. Attentional Control as a Moderator of the Relationship Between Difficulties Accessing Effective Emotion Regulation Strategies and Distress Tolerance.J Psychopathol Behav Assess. 2014;37(1):79-84. doi: 10.1007/s10862014-9433-2.

23. Viana AG, Raines EM, Woodward EC, Hanna AE, Walker R, Zvolensky MJ. The relationship between emotional clarity and suicidal ideation among trauma-exposed adolescents in inpatient psychiatric care: does distress tolerance matter? Cogn Behav Ther. 2019;48(5):430-44. doi: 10.1080/16506073.2018.1536163. [PubMed: 30457457].

24. Moghadam M, Makvandi B, Bakhtiyar Pour S, Ehteshamzadeh P, Naderi F. A Comparison of the Effectiveness of Dialectical Behavior Therapy (DBT) and Mindfulness Training in Improving Sleep Quality and Reducing Distress Tolerance in Drug-addicted Treatment Seekers. J Health Man \& Info. 2020;7(1):33-41.

25. Kabat-Zinn J. Mindfulness-based interventions in context: Past, present, and future. Clin Psychol: Sci Pract. 2003;10(2):144-56. doi: 10.1093/clipsy.bpg016.

26. Gross JJ. Emotion regulation: affective, cognitive, and social consequences. Psychophysiology. 2002;39(3):281-91. doi 10.1017/s0048577201393198. [PubMed: 12212647].

27. Russell BS, Hutchison M, Fusco A. Emotion Regulation Outcomes and Preliminary Feasibility Evidence From a Mindfulness Intervention for Adolescent Substance Use. J Child Adolesc Subst Abuse. 2019;28(1):21-31. doi: 10.1080/1067828x.2018.1561577.

28. Gratz KL, Roemer L. Multidimensional Assessment of Emotion Regulation and Dysregulation: Development, Factor Structure, and Initial Validation of the Difficulties in Emotion Reg ulation Scale. J Psychopathol Behav Assess. 2004;26(1):41-54. doi: 10.1023/b:Joba.0000007455.08539.94. 